\title{
Development of Instant Sinigang Powder from Katmon Fruit (Dellenia Philippinensis)
}

\author{
Marchelita Beverly Tappy ${ }^{1}$, Sophiya Celine Dellosa ${ }^{2}$, Teejay Malabonga ${ }^{3}$ \\ ${ }^{1,2,3}$ Adventist University of the Philippines \\ shaleybeverly07@gmail.com
}

\begin{abstract}
Katmon Fruit (Dillenia Philippinensis) is a fruit tree commonly use in the rural area in the Philippines. Katmon is eaten as fruit but is not very popular because of the unacceptable taste that resembles a green sour apple. The purpose of this study is to develop an instant sinigang powder as a base ingredient of sinigang and using the natural sour taste for sinigang dish. This study use katmon fruit, shiitake mushroom, garlic, iodized salt, and sugar to develop an instant sinigang mix powder. It were dehydrated using the Multi-Commodity Heat Pump Dryer for 13 hours. These were powdered using a grinder mixed with iodized salt and sugar. The nutrient content was computed using iFNRI online software. Thirty participants comprising: 10 faculty, 10 dormitory students, 10 senior high school students did the taste test. The results revealed that the product was liked very much in terms of color, texture, taste, aroma, and appearance. The instant sinigang powder is stored in a polyethylene metalized zip lock packaging $8.5 \times 14 \mathrm{~cm}$. The cost per serving is $\mathrm{PhP} 37.5$ It is cheaper and has more nutritional value compared to other products. The study recommending for more enhancement in terms of flavour of instant sinigang powder from katmon additional ingredient from natural sources to have more tasty and more nutritional content. This study also can help future researchers to have additional information about the katmon fruit.
\end{abstract}

Keywords: Instant Sinigang Powder; Katmon Fruit (Dillenia philippinensis); MultiCommodity Heat Pump Dryer; iFNRI.

\section{INTRODUCTION}

Katmon Fruit (Dillenia Philippinensis) is a fruit tree commonly use in the rural area in the Philippines. Katmon is eaten as fruit but is not very popular because of the unacceptable taste that resembles a green sour apple. The purpose of this study is to develop an instant sinigang powder as a base ingredient of sinigang and using the natural sour taste for sinigang dish. This 
study use katmon fruit, shiitake mushroom, garlic, iodized salt, and sugar to develop an instant sinigang mix powder. Katmon fruit originated in Asia including the Philippines and seems to be a native of the Philippines. Katmon is eaten as fruit but it is not very popular because of the unacceptable taste that resembles a green sour apple. But it is juicy and refreshing when eaten. The researchers got interested in the processing of katmon fruit to make an instant sinigang powder as a base ingredient. Because of its sour taste, a cookery with fish and vegetables and a souring ingredient. (Magdalita \& Abrigo, 2014). The goal of this study is the development of an instant sinigang powder from katmon fruit (Dillenia Philipinesis).

The objectives of this study are the following:

1. Develop a standardized recipe for instant sinigang powder through trial formulation,

2. Determine the shelf life through subjective evaluation,

3. Determine the nutrient content through iFNRI online software,

4. Compute the selling price through cost analysis,

5. Evaluate the acceptability of the product through subjective evaluation using 9-point Hedonic scale when used as a souring ingredient in sinigang, and

6. Compare the selling price with similar product in the market.

The general purpose of this study was to develop an instant sinigang powdered products for sinigang from katmon fruit. This includes the determination of shelf life, nutritional value, acceptability, and selling price. It was conducted to the students and faculty inside the campus. The nutrient content was only an estimate of the actual. The value was computed using the iFNRI online software. Time and budget constraints would not allow the researchers to do chemical analysis and observe the shelf life for a longer period of time. The acceptability of the product was determined through a subjective evaluation using the sensory attributes for adults.

\section{LITERATURE REVIEW}

The content of this chapter is the review of the literature of katmon fruit (Dillenia Philippinesis). The shelf life, major nutrients, selling price, acceptability, comparison of selling price. Dillenia philippinesis (katmon) is also known as elephant apple (Sharma \& Nath, 2014). Katmon grows in low to medium altitude forests throughout the Philippines but does not survive the cold climates of the uplands. The leaves are leathery shining, ovate, elliptic or 
oblong-ovate, about 12-25 centimeters long. It has flowers that are colored white. This tree is widely distributed all over the Philippines but is particularly native to the Babuyan group of islands and the Sulu archipelago (Lim, 2012). Katmon is an evergreen tree, growing up to approximately 6-15 meters high and is therefore small to medium in size. The bark is grayish brown in color and exhibits superficial fissures, while the upright or bent hole has slight buttresses (Lim, 2012). Its leaves, growing in an alternate pattern, are elliptical to ovate in shape and grows up to 25 centimeters in length; it has a leathery texture and shiny appearance, with dentate margins (Alberto \& Galvez, 2010). Its mature flowers can grow up to 15 centimeters in diameter; it has five large petals which are white in color and has a reddish center. The sepal is colored green and is the same number of the petals. There is abundance in the stamens and pistils in one mature flower (Castro, 2010). The fruit has a round shape, is completely enclosed by the sepals and is soft and fleshy (Lim, 2012).

The steps to plant Katmon Fruits is started with clearing the area where you want to plant your seedling with unwanted weeds and debris. Make sure that one-meter radius is kept free from other vegetation. Dig a plant hole with dimensions of at least $20 \mathrm{~cm} \times 20 \mathrm{~cm} \times 20 \mathrm{~cm}$. Plant the seedling at the proper depth. Root collar should be at level with or a little below the ground surface with the seedling oriented upward. Fill the hole with top or garden soil and press soil firmly around the base of the seedling. In plantation-making, seeding should maintain a twometer distance between seedlings if planters in a row of a three-meter distance from one strip to the next strip (Aboitiz, 2011).

The table 1 below shows the comparison of the shelf life of some local food seasoning.

Table 1. Comparison of shelf life

\begin{tabular}{ll}
\hline Product & Shelf life \\
\hline Brand A & 12 months \\
Brand B & 24 months \\
Brand C & 12 months \\
\hline
\end{tabular}

Source: Nearby Grocery Store

Most local seasoning can last up to 12-24 months especially if the product is dry and well packaged. Considering its shelf life, the product should be placed in a room temperature of 
$23^{\circ} \mathrm{C}$ and should be away from direct sunlight (Abeysinghe \& Illeperuma, 2010). Food seasonings do not spoil easily but when it gets longer the quality of the product will not be the same (Roberts, 2017). Product packaging may contribute to prolong shelf life, it allows the contents inside to stay fresh and safe for consumption, even after long hours of shipment and distribution. Products will require specific types of packaging materials that can protect its content for temperature (Vessella, 2015).

These table 2 and 3 discuss the nutritional value of each ingredient that will be needed in the development of katmon food seasoning. This served as the basis for the computation of the instant powdered seasoning. It includes Energy, Carbohydrate, Protein, and Fat, Calcium, Phosphorus and Iron, Vitamin A, Thiamin, Riboflavin, and Niacin.

Table 2. Nutritional Value of the Ingredients

\begin{tabular}{lcccc}
\hline \multicolumn{1}{c}{$\begin{array}{c}\text { Name of } \\
\text { ingredient }\end{array}$} & $\begin{array}{c}\text { Energy } \\
\text { Kcal }\end{array}$ & CHO & CHON & Fat \\
\hline Katmon & 33 & 7.4 & 0.3 & 0.2 \\
Mushroom & 330 & 64.6 & 16.0 & 0.9 \\
Garlic & 129 & 24.6 & 7.0 & 0.3 \\
Salt & 128 & 31.9 & 0.0 & 0.0 \\
Sugar & 400 & 99.9 & 0.0 & 0.0 \\
\hline
\end{tabular}

Source: Food Composition Table

Table 3 Nutritional Value of the Ingredients

\begin{tabular}{cccccccc}
\hline & Minerals & \multicolumn{5}{c}{ Vitamins } & Moisture \\
$\mathbf{C a}$ & $\mathbf{P}$ & $\mathbf{F e}$ & Vit. A & B1 & B2 & B3 & \\
\hline $\mathbf{2 8}$ & 5 & 0.1 & 4 & 0.02 & 0.04 & 0.2 & 4 \\
$\mathbf{5 1}$ & 223 & 0.4 & 0 & 0.02 & 0.10 & 1.8 & 14.9 \\
$\mathbf{2 8}$ & 121 & 1.2 & 0 & 0.23 & 0.08 & 0.4 & - \\
$\mathbf{2 6 7}$ & 27 & 5.5 & $\operatorname{Tr}$ & $\operatorname{Tr}$ & $\operatorname{Tr}$ & $\operatorname{Tr}$ & 10.3 \\
$\mathbf{0}$ & 0 & 0.0 & 0 & $\operatorname{Tr}$ & 0.01 & $\operatorname{Tr}$ & - \\
\hline
\end{tabular}

Source: Food Composition Table 
Food seasoning in the local is commonly sold using a sachet packaging. Prices may vary depending on the amount per sachet. The sachet is used as the primary packaging of the product. When it is already at grocery stores they sell it using a secondary packaging that may cost in the total amount of weight product as shown by table 4 . The prices of these different brands of local food seasonings are from a nearby market, the comparison of each product is based on their weight and selling price. Brand A is a local product that uses a sachet as its primary packaging and plastic for its secondary packaging that has a total weight of 40 grams and it is good for 1 liter of water. Major ingredients are iodized salt, MSG, sugar, chicken fat, flavor enhancer, garlic, onion, spices, natural and nature identical flavors. Brand B is a local product that uses a medium size sachet as its primary packaging that has a weight of 50 grams per selling and used for 1.5 liters of water. It has 3 flavor ingredients they are meat, bones and special spices. Brand $\mathrm{C}$ is a product that uses small sachet that has a weight of $22 \mathrm{~g}$ per selling and it is good for 1 liter of water. It has a variety of flavor. Major ingredients are Iodized salt, sugar, Acidulant (citric acid), monosodium glutamate.

Table 4 Prices of some brand of local food seasoning

\begin{tabular}{lll}
\hline \multicolumn{1}{c}{ Product } & \multicolumn{1}{c}{ Liter } & \multicolumn{1}{c}{ Amount } \\
\hline Brand A & 1 liter & PHP 21 \\
Brand B & 1.5 liters & PHP 34.16 \\
Brand C & 1 liter & PHP 10.50 \\
\hline
\end{tabular}

Source: Grocery Store Price Index

Food seasoning is very well used in the Philippines especially in the local Filipino dish. The acceptability of the product will depend on its marketing strategy that will be used and the impact to its respondents. Most of the people are also considering the product's nutritional value (Abdel-Moemin, 2014). Food acceptance is a complex field influenced by many factors the rate of appearance, texture, aroma, and taste of the product. This method of evaluation will help the researcher to know which part is needed to be improved or change (Williams, 2012). Shiitake Mushroom (Lentinula edodes). Shiitake mushroom is neither plants nor animals but has their own separate category as a life form. The part of shiitake mushrooms that we eat is 
actually the fruit of the fungus. New research has shown that a small amount of dried mushroom can provide measurable anti-inflammatory benefits (Mateljan, 2017). Aqueous extracts of dried shiitake mushrooms are used as taste and flavor enhancers for meat formulations (Dermiki \& Phanphensophon, 2013). It gives gravies, sauces, and stews the taste known as umami (Food, 2016). Shiitake mushrooms have antiviral, antibacterial and anti-fungal properties. They also help to control blood sugar level and reduce inflammation within the body. Shiitake mushrooms contain many chemical compounds that protect the DNA from oxidative damage, which is partly why they're so beneficial (Axe, 2017).

Part of the lily, allium, family of which onions are also a member, garlic is one of the most indispensable ingredients around and plays a central role in the Mediterranean and Asian cookery. When it is cooked it becomes more mellow and creamy (Lewin, 2010). The functional benefits of garlic are its antimicrobial activity, anticancer activity etc. (Rahman, 2010).

Iodine is an essential micronutrient required a small amount for the normal physiological function of the human. Iodized salt is a table salt with a mixture of a small amount of the various element iodine. The ingestion of iodine prevents iodine deficiency (Ohlhorst \& Slavin, 2012). From a culinary perspective, salt has many desirable properties. Added salt improves the sensory properties of virtually every food that humans consume, and it is cheap. Salt imparts more than just a salt taste to overall food flavor. It works with a variety of foods (soups, rice, eggs and potato chips), salt was found to improve the perception of product thickness, enhance sweetness, mask metallic, and round out overall flavor while improving flavor intensity (Bereen, 2010).

The role of sugar in the food industry is described based on its chemical and physical properties. In the chemical aspects of sugar, it includes sweetness and flavor, the reactions of sucrose and inverts sugar, caramel formation, and antioxidant effect. Physical properties of sugar are osmotic pressure, crystallization and solubility, hygroscopicity, thermodynamic properties, viscosity, grain size, bulk handling and such miscellaneous properties as stickiness and thermal and electrical conductivity (Cotton, Rebers, \& Rorabaugh, 2017). Sugar acts as a preservative that prevents or slow the growth of bacteria. It also helps to prolong the shelf life of many foods on supermarket shelves by acting as a humectant (Silcock, 2012).

These terms was used by the researchers in this study;

1. Katmon Fruit are quite fleshy and have a taste similar to green sour apples. 
2. iFNRI is a computer-based application for researcher performing product and recipe development.

3. Shelf Life is the length of time that food may be stored and still be good to eat at a room temperature.

4. Acceptability is the evaluation of product according to its texture, color, aroma, and flavor using a 9-point hedonic scale.

5. Selling Price is the computed exchange value, with a markup factor of $2.5 \%$ based on 1 pack with a net weight of 45 grams.

6. Palatability is the acceptability of the product in terms of color, aroma, appearance, and taste measured using a 9-point Hedonic scale.

7. Nutritional Value is the nutrient content in one serving of the product computed using the iFNRI application.

8. Instant Sinigang Powder is a ready-made product from katmon fruit as based ingredient that can give a sour taste and aroma in sinigang and made for convenient use.

9. Multi Commodity Heat Pump Dryer system was designed, fabricated, assembled and evaluated following basic refrigeration and air conditioning

\section{METHODS}

Materials are the major or minor thing used throughout the experimentation of the product. It is essential for the development of the products from the farm to the market.

1. Multi-Commodity Heat Pump Dryer. The major important equipment for dehydration of Katmon fruit is the Multi-Commodity Heat Pump Dryer. This was used to dehydrate Katmon fruit and garlic. The equipment is capable of the reducing the water activity of food thus lengthening the shelf life of the product. The equipment can hold 24 trays at a time.

2. Grinder. After the dehydration of katmon and garlic, a grinder was used to ground katmon and garlic into the very fine texture.

3. Weighing Scale. A weighing scales was used to measure the quantity of each ingredient. The measurement of weight is a more accurate way of standardizing the quantity compared to volume or household measurement. The weight of the ingredients was used also for the computation of nutritional value and the selling price. 
Utensils:

1. Knife, the knife was used to cut and peel Katmon fruit and slicing the garlic.

2. Chopping board, the chopping board was used during the peeling and cutting process of katmon and garlic.

3. Stainless bowl, the stainless bowl was used as a container during the preparation of katmon and garlic

4. Wire whisk, the wire wisk is used together in the mixing process all the ingredients of the product

5. Measuring cup/ measuring spoon, this was used to measure the ingredient in household portions

6. Sauce Pan, the saucepan was used in cooking of sinigang recipe.

Ingredients:

1. Katmon powder. Katmon powder is the dehydrated and pound Katmon fruit that served as the main ingredient of the product.

2. Shitake Mushroom powder. Shiitake mushroom powdered contributed to the enhancement of flavor and nutritional value of the product. Processed by grinding the dried form.

3. Dried Garlic powder. Garlic contributed to the enhancement of flavor and aroma. Processed by dehydrating and pounding.

4. Iodized Salt. The iodized salt contributed to the enhancement of flavor and nutritional value of the product.

5. Sugar. The sugar enhanced the umami taste of the product

\section{Methods and Process Flow}

1. Prepare Katmon Fruit. The newly harvested Katmon was prepared by removing the skin and removing the hairy part inside the fruit. It was washed with water before it was flaked, separating the cleavage part. The fruit was cut into smaller pieces to fasten the drying process. 
2. Dehydrate Katmon fruit and Garlic. The flaked Katmon fruit and chopped garlic were placed on a tray layered with cloth to prevent the Katmon from sticking. The Katmon fruit and garlic was dehydrated for 13 hours.

3. Grind ingredients. After the dehydration process, Katmon, garlic and shiitake mushroom were dehydrated one at a time using a heavy duty grinder.

4. Identify the Ingredients. Other ingredients for a palatable product were identified choosing the best quality. The basic ingredient Katmon, powdered shiitake mushroom, powdered garlic, iodized salt and refined sugar were the ingredients identified as the final ingredients of the product.

The list of ingredients in household measurements per trial is shown at Table 5.

Table 5. List of Ingredients in Household Measurements per Trial

\begin{tabular}{lccccc}
\hline \multicolumn{1}{c}{ Ingredient } & Trial 1 & Trial 2 & Trial 3 & Trial 4 & Trial 5 \\
\hline Katmon & $2 \mathrm{Tbsp}$ & $5 \mathrm{Tbsp}$ & $5 \mathrm{Tbsp}$ & $5 \mathrm{Tbsp}$ & $5 \mathrm{Tbsp}$ \\
Mushroom & - & $1 \mathrm{Tbsp}$ & $1 \mathrm{Tbsp}$ & $1 \mathrm{Tbsp}$ & $1 \mathrm{Tbsp}$ \\
Garlic & $1 / 4 \mathrm{Tbsp}$ & $11 / 2 \mathrm{Tbsp}$ & $1 / 2 \mathrm{Tbsp}$ & $1 / 2 \mathrm{Tbsp}$ & $1 \mathrm{Tbsp}$ \\
Iodized Salt & $1 / 8 \mathrm{Tsp}$ & $1 / 4 \mathrm{tsp}$ & $1 / 2 \mathrm{tsp}$ & $1 / 2 \mathrm{tsp}$ & $1 \mathrm{tsp}$ \\
Sugar & $1 / 2 \mathrm{tsp}$ & $1 / 4 \mathrm{tsp}$ & $1 / 4 \mathrm{tsp}$ & $1 / 4 \mathrm{tsp}$ & $1 / 2 \mathrm{tsp}$ \\
\hline
\end{tabular}

In the first trial, the sourness of the product was tried in two liters of hot water. The proportion of ingredients was two tablespoons of Katmon powder, 1/4 tablespoon of garlic, 1/8 tsp of iodized salt and 1/8 tsp as well for sugar. Two liters of water was boiled for about three minutes and instant sinigang powder was added. The color of the water is light brown and but it has a lot of residue, but it is evident that the sour will make a good sinigang powder.

For the second trial, the researchers included one kilo of vegetables for the ingredients of the sinigang dish in three liters of water, five tablespoons of Katmon powder, one tablespoon of shiitake mushroom, 1 1/2 tablespoon of garlic, $1 / 4$ teaspoon iodized salt, and 1/4 teaspoon of sugar. The researchers boiled the vegetables for 5 minutes and add the instant sinigang powder. The sour taste is acceptable but it has a lot of residue.

In the third trial, the researchers used the same ingredient from the second trial but the amount of water and garlic was reduced and there was an additional amount of salt. Two liters of water was prepared, five tablespoons of Katmon and one tablespoon of shiitake mushroom, $1 / 2$ 
tablespoon of garlic, $1 / 2$ teaspoon of iodized salt and $1 / 4$ teaspoon of sugar. One half kilo of vegetables was used for this trial. There was an improvement in terms of the taste compared to the second trial.

For the fourth trial, there are no changes with the ingredients of instant sinigang powder. The researchers use the same amount of each ingredient that was done during the third trial, but there is an adjustment with the water that was used. One liter of water was used, 5 tablespoons of Katmon powder, 1 tablespoon of shiitake mushroom, 1/2 tablespoon of garlic, $1 / 2$ teaspoon of iodized salt and $1 / 4$ teaspoon of sugar and the same vegetables. This time the sinigang is too sour but the residue were not present anymore due to the improvement in the grinding process. The fifth trial and final trial formulation, same ingredients are used but there is the additional quantity of salt and sugar. Five tablespoons of Katmon powder, one tablespoon of shiitake mushroom, one tablespoon of garlic, one teaspoon of salt, and $1 / 2$ teaspoon of sugar. The researchers use 1.5 liters of water and same ingredients of vegetables for sinigang dish. The result is highly in terms of all the palatability factors. This served as the basis for the standardization of the product.

After mixing all the ingredients the researchers weighed the product by using a digital weighing scale according to the desired quantity and afterward placed inside a packaging material. The finished product was well sealed in a Polyethylene metalized ziplock. The physical changes for any chemical reaction or presence of the microorganism were observed for 2 months of observation in a room temperature.

Based on the quantity and quality of the product the researchers had determined the nutritional value of the instant sinigang powder. The researchers used the iFNRI online software as a tool to determine the nutritional value of the product. Since the dehydrated Katmon and garlic are not available in the iFNRI. The nutritional content of the form was derived from values of the fresh ingredients. Since the nutritional value was not reduced by the dehydration process, values from fresh ingredients were used as the basis for the computation of the dried ingredients. The nutritional value of the 4,700 grams were assured to be the value of the 310 grams of dehydrated Katmon. Thus to compute the value per 100 gram, the nutrient content in fresh Katmon was divided by the weight of dehydrated ingredient times one hundred. 


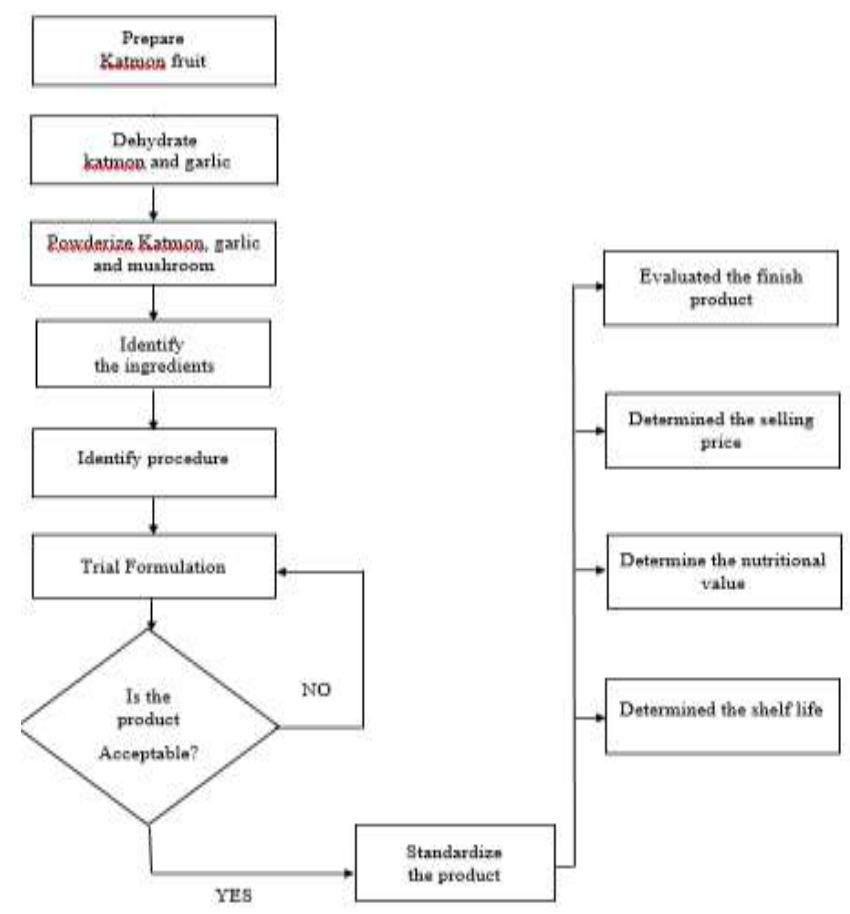

Figure 1 The process of the product development from the preparation to the finished product

The determined selling price for the market the researchers considered the quantity of ingredients that was used, the type of material during the packaging of the final product. Expenses from the dehydration of Katmon fruit and garlic was included same with the powdering of Katmon, Shiitake mushroom and garlic expenses in grinding.

The last part of the procedures was the evaluated finish product by using a subjective test and the samples were given to 30 people and were divided into 3 groups, 10 faculties, 10 college and 10 senior high school students. It helps the researchers determined if the final product is successful over the actual experimentation. The success product is by its acceptability for the people and the market.

Figure 1 above is the process of the product development from the preparation to the finished product.

\section{RESULTS}

Table 6 shows that the standardization amount of each ingredient that the researchers used for their final product of instant sinigang powder. The standardized recipe is based on the results 
of trials and experimentation that come up after the researchers made many trials. The product was standardized by preparing the product three times using the same proportion of ingredients and procedure. This was done to make sure that the quality of the product was not a result of chance. The total weight of the standardize quantity of the product is 45 grams. The grams content is good for 1.5 liters of water and $1 / 2$ kilo of vegetables with the total serving is 10 .

\section{Table 6. Standardized Ingredients for Instant Sinigang Powder from Katmon fruit (Dillenia Philippinesis).}

\begin{tabular}{lcc}
\hline \multicolumn{1}{c}{ Ingredients } & $\begin{array}{c}\text { Household } \\
\text { Measurement }\end{array}$ & Weight \\
\hline Katmon & $5 \mathrm{Tbsp}$ & 30 grams \\
Mushroom & $1 \mathrm{Tbsp}$ & 5 grams \\
Garlic & $1 \mathrm{Tbsp}$ & 5 grams \\
Iodized salt & $1 \mathrm{Tsp}$ & 3 grams \\
Refined Sugar & $1 / 2 \mathrm{Tsp}$ & 2 grams \\
\hline
\end{tabular}

The time of observation was two months in which the product was observed to have no physical changes. The color remained slightly brown in a Polyethylene metalized packaging in a room temperature. The sour aroma, and the textures remain the same. The maximum shelf-life of the product was not determined because of time constraint.

The result of the nutritional value of the finished product as computed using the application iFNRI that is shown in 7 . The result shows from table 8 that instant sinigang powder contains, $191 \mathrm{kcal}, 2.9$ grams of protein and 1 gram of fat, 141 grams of calcium, 47mg of phosphorus, and $1.1 \mathrm{mg}$ of Iron, vitamin $\mathrm{A}$ is $18(\mu \mathrm{RE})$ for thiamin $0.12 \mathrm{mg}$, riboflavin $0.07 \mathrm{mg}$, Niacin 1.4 and vitamin C 19mg. these nutrients were mainly contributed by Katmon fruit.

Tabel 7. The nutritional value of the finished product as computed using the application iFNRI

\begin{tabular}{cccccccc}
\hline Ingredients & AP $(\mathbf{g})$ & $\mathbf{E P}$ & $\boldsymbol{\%} \mathbf{E P}$ & $\begin{array}{c}\text { Energy } \\
(\mathbf{k c a l})\end{array}$ & $\begin{array}{c}\text { CHON } \\
(\mathbf{g})\end{array}$ & $\begin{array}{c}\text { Fat } \\
(\mathbf{g})\end{array}$ & $\begin{array}{c}\text { CHO } \\
(\mathbf{g})\end{array}$ \\
\hline Katmon fruit & 30 & 30 & 100 & 150 & 1.4 & 0.9 & 33.6 \\
\hline Dried mushroom & 5 & 5 & 100 & 17 & 0.8 & 0 & 3.2 \\
\hline Dried garlic & 5 & 5 & 100 & 13 & $0 . / 7$ & 0 & 2.5 \\
\hline Salt & 3 & 3 & 100 & 4 & 0 & 0 & 1 \\
\hline
\end{tabular}




\begin{tabular}{cccccccc}
\hline $\begin{array}{c}\text { Refined White } \\
\text { Sugar }\end{array}$ & 2 & 2 & 100 & 8 & 0 & 0 & 2 \\
\hline TOTAL & & & & 191 & 2.9 & 1 & 42.2 \\
\hline
\end{tabular}

Tabel 8. Computed Nutritional Value of the product per packaging 45 grams(10 servings

\begin{tabular}{ccccccccc}
\hline Ingredients & $\begin{array}{c}\text { Cal } \\
(\mathbf{g})\end{array}$ & $\begin{array}{c}\mathbf{P} \\
(\mathbf{m g})\end{array}$ & $\begin{array}{c}\text { Fe } \\
(\mathbf{m g})\end{array}$ & $\begin{array}{c}\text { Vit. A } \\
(\boldsymbol{\mu} \mathbf{R E})\end{array}$ & $\begin{array}{c}\text { B1 } \\
(\mathbf{m g})\end{array}$ & $\begin{array}{c}\text { B2 } \\
(\mathbf{m g})\end{array}$ & $\begin{array}{c}\text { B3 } \\
(\mathbf{m g})\end{array}$ & Vit. C \\
\hline Katmon Fruit & 127 & 23 & 0.5 & 18 & 0.09 & 0.01 & 0.1 & 18 \\
Dried mushroom & 3 & 11 & 0.3 & 0 & 0 & 0.05 & 1.1 & 0 \\
Dried garlic & 3 & 12 & 0.1 & 0 & 0.02 & 0.01 & 0.02 & 1 \\
Salt & 8 & 1 & 0.2 & 0 & 0 & 0 & 0 & 0 \\
Refined white sugar & 0 & 0 & 0 & 0 & 0 & 0 & 0 & 0 \\
TOTAL & 141 & 47 & 1.1 & 18 & 0.12 & 0.07 & 1.4 & 19 \\
\hline
\end{tabular}

The selling price of the product is determined by the computation of each ingredient that the researchers used in the finished product, packaging, and other expenses throughout the experimentation such as dehydration process and grinding. The table 9 below shows the computation of prices. That include the quantity, description, and cost of the ingredients per packaging. The computed price of finish product is based on the mark up of 1.5 The result of selling price is based on 10 yields with 450 grams of dehydrated ingredients and the cost is PHP 89.64. Additional expenses are dehydrator and grinding. The expenses are 148.33 pesos and 1.12 pesos per ziplock. The total is 250.57 pesos and $1.5 \%$ for markup value. The result comes up from the price per pack which is 37.5 pesos per 45 grams.

Table 9. Value of the Ingredients used and selling Price per pack

\begin{tabular}{lllll}
\hline Quantity & Ingredients & Description & Price per gram & Total Cost \\
\hline $\mathbf{3 0 0 g}$ & Katmon & Dehydrated & Php:0.16 & Php:50 \\
$\mathbf{5 0 g}$ & Mushroom & Dehydrated & Php:0.65 & Php:32.5 \\
$\mathbf{5 0 g}$ & Garlic & Dehydrated & Php:0.1 & Php:5 \\
$\mathbf{3 0 g}$ & Salt & Powdered & Php:0.04 & Php: 1.32 \\
$\mathbf{2 0 g}$ & Sugar & White & Php:0.06 & Php: 1.12 \\
Other expenses & & & \\
$\mathbf{1 0}$ pc & Packaging & Ziplock & & Php: 12.3 \\
\hline
\end{tabular}




\begin{tabular}{llcc}
\hline 13 hours & $\begin{array}{l}\text { Katmon, } \\
\text { Mushroom, } \\
\text { Garlic }\end{array}$ & Dehydration/grinding & Php:148.33 \\
\hline
\end{tabular}

Figure 2 shows the result of the product evaluation in determining the acceptability.

It is shown in the results that based on color 53.3\% liked extremely, 23.3\% liked very much, $20 \%$ liked moderately and only $3.3 \%$ liked slightly. For the result based on texture $26.6 \%$ were liked extremely, $53.3 \%$ liked very much, $10 \%$ liked moderately and of 3.3\% for liked slightly and same with neither like nor dislike. The result based on taste is $30 \%$ for liked extremely, $33.3 \%$ liked very much, $26.6 \%$ liked moderately, and $10 \%$ for liked slightly. The result for appearance is $46.6 \%$ for liked extremely, $30 \%$ for liked very much and $23.3 \%$ for liked moderately. The result shows there is a high percentage of liked extremely and liked very much. The highest percentage of acceptability for the characteristics is from appearance.

Computation

Markup Value: 1.5.

Total Cost: 250.57

Yield: 10
Selling Price: $250.57 \times 1.5=375.85$

$250.57+375.85=625.85$

Selling Price: Php: 37.5 per $45 \mathrm{~g}$ 


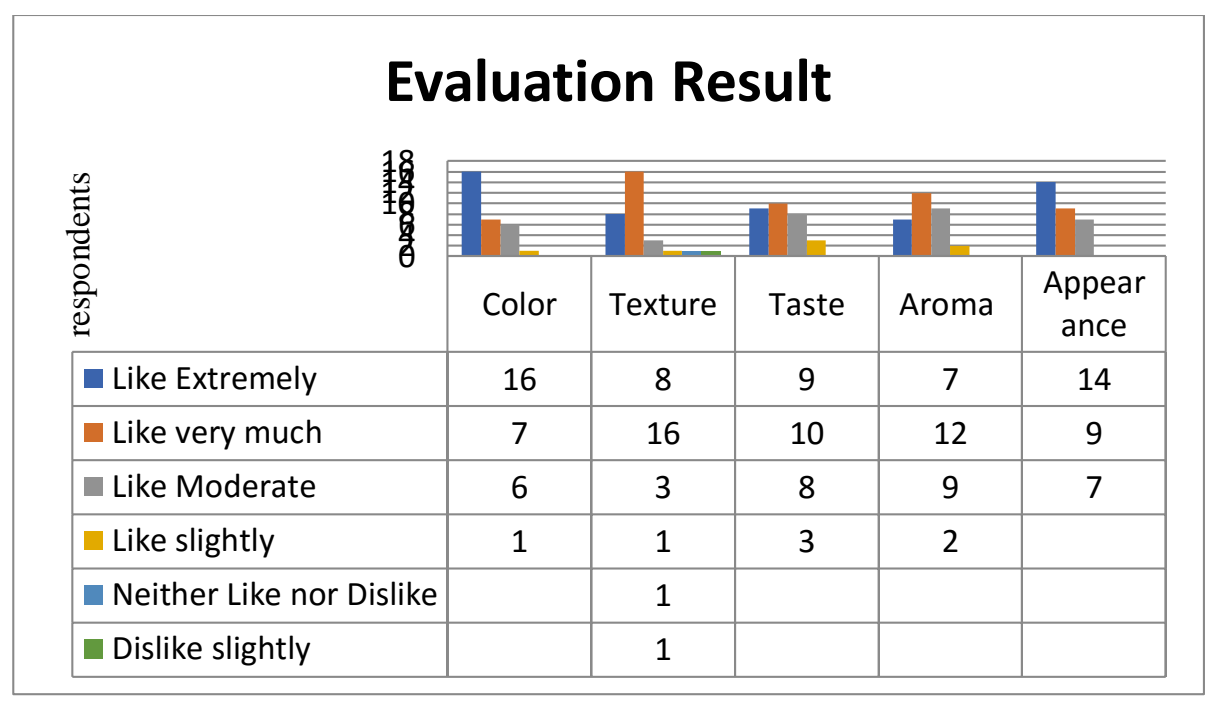

Figure 2. The result of sensory attributes evaluation age 19 and above

\section{DISCUSSION}

Sinigang is one of the most popular recipes in the Philippines. The researchers were able to develop Katmon as the base ingredient of sinigang powder and using solely the natural sour taste for sinigang dish. Majority of the respondent through evaluation gave the product a like extremely evaluation in terms of aroma, color, texture and taste of the sinigang. The product has been accepted base on the result of the evaluation. The comment of some evaluators proved that katmon fruit is edible as an instant sinigang powder. The shelf life of instant sinigang powder from Katmon fruit was observed for two months, the product remains to have no physical changes and maintains its good quality. The shelf could have been longer but the researchers failed to prove in this study because of the lack of time. The nutritional value of the product is determined. The study shows that finish product has vitamins and minerals content. It can give essential nutrient that needed. The selling price of the product, after the computation of all expenses is 37.5 pesos per pack of 45 grams with a markup value of $1.5 \%$.

\section{Conclusion}

The product is shelf stable because it is well dehydrated. The packaging is safe but it is not allowed to exposure in sunlight nor heat. Based on the result of the study instant sinigang powder from Katmon fruit is a product comparable with other sinigang mix that uses other chemicals to enhance the sourness of the seasoning. The researchers concludes that the product 
is acceptable. The development of instant sinigang powder from Katmon is possible as base ingredient for sinigang mix product.

\section{Recommendation}

The study did not maximize the uses of Katmon fruit for its better development as sinigang mix. The skin and fruit meat are both edible but the researchers used the fruit meat only. For the further development of Katmon fruit, the researchers recommended the maximized use of Katmon fruit. The nutritional value of Katmon fruit (Dillenia Philippinesis) is based on the fresh fruit in iFNRI. The finished product is dehydrated and ground. For future study, the researchers recommend a chemical analysis of the nutritional value of dehydrated Katmon fruit at the Food and Nutrition Research Institute to reach and to obtain the exact value of the nutrient of the product. For more enhancement in terms of flavor of instant sinigang powder from Katmon additional ingredient from natural sources to have more tasty and more nutritional content if the product as sinigang mix. The shelf life of the product is not exactly determined by the researchers due to the limited time of observation. The researchers observed for only two months and two weeks. For the future study, the researchers recommend a longer period of time to determine the exact shelf life of the product. The observation in a change of taste, the color of the product is important to observe. Characteristic changes can help for safety consumption. The researchers used Polyethylene metalized ziplock for the packaging of finished product. The use of other packaging is recommended, like canisters and another type of packaging material that can help for better prevention of spoilage.

\section{REFERENCES}

Abdel-Moemin, A. R. (2014). Consumer Satisfaction and nutrient profile of reformulated dry soups. Nutrition and Food Science, 1-2.

Abeysinghe, C., \& Illeperuma, C. (2010). Formulation of an MSG (Monosodium Glutamate) free instant vegetable soup mix. Department of Food and Science Technology, 2.

Aboitiz, R. (2011). Tree of the month part 2: Katmon (Dilenia philippinesis Rolfe). Quezon City: Foundation Inc.

Alberto, A., \& Galvez, C. (2010). Handbook on Trees. Quezon City: Rex Books Store, Inc. Axe, D. (2017, January). Dr. Axe Food Medicine. 
Bereen, C. (2010). Taste and Flavor Roles of Sodium in Foods: A Unique Challenge to Reducing Sodium Intake. Washington (DC): National Academies Press (US).

Castro, I. (2010). A Guide to Families of Comon Flowering Plants in the Philippines. Quezon City: The University of the Philippines Press.

Cotton, R., Rebers, P., \& Rorabaugh, G. (2017). Use of Sugars and other Carbohydrates in the Food Industry. Advances in Chemistry, 3.

Department of Agriculture. (2010). Katmon Fruits (Dillenia Philipinesis).

Dermiki, M., \& Phanphensophon, N. (2013). Contributions of non-volatile and volatile compounds to the umami tasta and overall falvor of shiitake mushroom extracts and their application as flavor enhancers in cooked minced meat. Food Chem, 141.

Food, H. H. (2016, July 1). Harmony House.

Lewin, J. (2010, November). The Health Benefits of Garlic.

Lim, T. (2012). Edible Medicinal and Non Medicinal Plants (Vol. 2). New York: Shringer Science Business Media.

Magdalita, P. M., \& Abrigo, M. I. (2014). Phenotypic evaluation of some promising rare fruit crops in the Philippines. Philippine Science Letter, 7(2), 376.

Mateljan, G. (2017). The World's healthiest Foods. N/A: Midpoint Trade Books Inc.

Ohlhorst, S. D., \& Slavin, M. (2012, March). Use of Iodized Salt in Process Foods in Select Countries Around the World and the Role of Food Processors. Comprehensive Reviews in Food Science and Food Safety, 233-284.

Palmar. (2011). Katmon.

Rahman, M. (2010). Allicin and other Functional Active Components in Garlic: Health Benefits and Bioavailability. International Journal of Food Properties, 245.

Roberts, A. (2017). StillTasty.

Sharma, H., \& Nath, L. (2014). Study of the Effect of Dillenia indicca Fruit. International Scholarly Research Notices, 6.

Silcock, P. (2012). The Functional Role of Sugar in Food.

Vessella, V. (2015, September 22). Packaging Considerations for the Food Industry.

Williams, A. (2012). Food Acceptability. Understanding Natural Flavors, pp 29-45. 